\title{
EDITORIAL INDIAN DRUGS MARCH 2018
}

Dear Reader,

On the $22^{\text {nd }}$ of February this year, INDIAN DRUGS celebrated its 55th Annual Day at the IIT Bombay campus in Powai. 55 years of publishing a Scientific Journal regularly every month is truly an accomplishment of which I am grateful to be able to contribute to. I sincerely appreciate all our Editorial Advisory Board and Editorial Board Members and the large number of reviewers who took time off and actively participated in the celebrations. The enthusiasm and support of all present at this grand event is an indication of the commitment to the cause of improving the quality of pharmaceutical

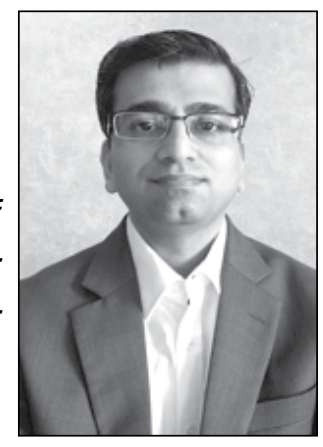
research being conducted in India. The continued commitment of a large number of our Editorial Advisory Board and Editorial Board members has been a constant source of motivation for all of us in the Editorial Committee of INDIAN DRUGS to improve the publication.

The objective of the founding Editorial team of INDIAN DRUGS was to provide a platform for academia and industry in India to present their research. In the early sixties, there were only a handful of scientific publications in the world that provided pharmaceutical researchers the opportunity to publish original research. The foresight of the leadership at IDMA to recognize this need and initiate the publications is commendable.

We continuously endeavour to provide young researchers the opportunity to publish their research while we continue upgrading standards set by previous Editorial Boards. Our reviewers carry on their commitment to review submitted manuscripts and provide guidance and encouragement to young researchers to improve the quality and presentation of their research findings. We receive approximately 450+ manuscripts annually for review in the six broad pharmaceutical disciplines with an acceptance rate of approximately $25 \%$. Since we have facilitated online submissions and review, the number of manuscript submissions have been growing annually. Hence, we extend an invitation to senior pharmaceutical researchers to join us as reviewers and existing reviewers to recommend upcoming research scientists in their institutions to join us in this endeavor to improve the quality of pharmaceutical research in INDIA.

While academic researchers in India too, have become "Impact factor Centric" in their choice of journals where they choose to publish, it is a matter of pride that more Indian pharmaceutical researchers have been able to publish in high impact journals. We are grateful that these researchers continue to submit manuscripts to INDIAN DRUGS and credit their early successes to the wide visibility of their manuscripts published in INDIAN DRUGS. 18 international databases currently abstract papers published in Indian Drugs and more databases are showing keen interest. INDIAN DRUGS is also listed in Journals approved by UGC for CAS and Appointment of University Teachers.

Print copies of the journal are distributed free of cost to over 1000 members of IDMA and some of the larger members of IDMA subscribe to multiple copies of the INDIAN DRUGS for their scientists at different locations. Papers published in INDIAN DRUGS are also available online for 
easy access to reviewers for reference. We are extremely happy to provide this interface for academic and industrial scientists to showcase their research capabilities. We strongly urge academia to use this platform for their benefit.

We invite one and all to join us and work together in the interest of the industry and our nation.

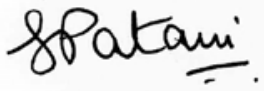

Dr. George Patani, Associate Editor, Indian Drugs

9

\section{About The Guest Editor}

Dr George Patani, is a Pharmacist from the College of Pharmaceutical Sciences, Manipal and completed his Masters in Medicinal Chemistry and Ph.D. in Drug Delivery from the Rutgers, The State University of New Jersey. He has approx. 18 years' experience at the INGA group of companies, developing and manufacturing phytochemical APIs and finished dose formulations. This experience has included an extensive record of project leadership in pharmaceutical formulation development and regulatory affairs. He has authored a number of scientific publications and book chapters with over a 1000+ citations from individual manuscripts.

Dr Patani is currently the Treasurer of the Indian Drug Manufacturers' Association for 2017-18, Chairman IDMA's publication committee since 2012 and Chairman of IDMA's Industry Institute Interaction Committee since 2014. He has been a recipient of the Outstanding Alumnus Award 2016 and Distinguished Alumnus Award 2005 from Manipal University. He has served on various committees such as the Crude Drugs and Herbal Products Committee of the Indian Pharmacopoeial Commission and the Reach Monitoring Committee of the TIFAC CORE in genomics at Manipal Academy of Higher Education etc.

百 